\section{Diaminobenzidine photoconversion is a suitable tool for tracking the intracellular location of fluorescently labelled nanoparticles at transmission electron microscopy}

\author{
M. Malatesta,' M. Giagnacovo, ${ }^{2}$ \\ M. Costanzo, ${ }^{1}$ B. Conti, ${ }^{3}$ I. Genta, ${ }^{3}$ \\ R. Dorati, ${ }^{3}$ V. Galimberti, ${ }^{2}$ \\ M. Biggiogera, ${ }^{2,4}$ C. Zancanaro' \\ 'Department of Neurological, \\ Neuropsychological, Morphological and \\ Movement Sciences, University of \\ Verona; 'Department of Biology and \\ Biotechnology, Laboratory of Cell \\ Biology, University of Pavia; ${ }^{3}$ Department \\ of Drug Sciences, University of Pavia; \\ ${ }^{4} \mathrm{CNR}$ Institute of Molecular Genetics, \\ Pavia, Italy
}

\section{Abstract}

Chitosan-based nanoparticles (NPs) deserve particular attention as suitable drug carriers in the field of pharmaceutics, since they are able to protect the encapsulated drugs and/or improve their efficacy by making them able to cross biological barriers (such as the blood-brain barrier) and reach their intracellular target sites. Understanding the intracellular location of NPs is crucial for designing drug delivery strategies. In this study, fluorescently-labelled chitosan NPs were administered in vitro to a neuronal cell line, and diaminobenzidine (DAB) photoconversion was applied to correlate fluorescence and transmission electron microscopy to precisely describe the NPs intracellular fate. This technique allowed to demonstrate that chitosan NPs easily enter neuronal cells, predominantly by endocytosis; they were found both inside membrane-bounded vesicles and free in the cytosol, and were observed to accumulate around the cell nucleus.

\section{Introduction}

Nanoparticles (NPs) have been attracting increasing interest for their potential in biomedical applications such as drug delivery, tissue engineering and medical imaging. In fact, their unique properties (e.g., small size and large surface area) enable their passage through biological barriers as well as their accumulation at the target sites.

Chitosan-based NPs deserve particular attention in the field of pharmaceutics and biomaterials due to many advantageous features: chitosan may be obtained from natural products, ${ }^{1}$ it is enzymatically degradable (although mostly by enzymes that are not ubiquitously expressed by mammalian cells), ${ }^{24}$ can be easily functionalized and/or complexed ${ }^{5}$ and, above all, it has a relatively low toxicity, in comparison with most polycations. Among the available NP tools for drug delivery, chitosan NPs are especially promising insofar they are able to protect the encapsulated drugs and/or improve drug bioavailability by modifying its pharmacokinetics. ${ }^{6,7}$

In particular, chitosan NPs were shown to be suitable for delivering molecules characterised by low stability, such as peptides, proteins, oligonucleotides and plasmids; chitosan NPs protect these molecules from denaturation or enzymatic degradation in the biological environment ${ }^{8}$ and increase their efficacy by making them able to cross biological barriers and reach the intracellular or intranuclear target sites. ${ }^{9-12}$ Chitosan-based NPs enter the cells by various endocytic processes, which may vary in different cell types and have not been fully identified: their uptake appears to occur predominantly by adsorptive endocytosis, but also clathrin- and caveolin-mediated pathways as well as clathrin- and caveolin-independent endocytosis may be involved. ${ }^{13-19}$

Besides the uptake mechanism, the intracellular location of NPs is also crucial for their biological effect, especially where drugs are targeted to intracellular targets. Understanding the intracellular localization of NPs with respect to their uptake mechanism is therefore essential in designing drug delivery strategies. Unfortunately, precise intracellular localization of NPs is difficult to assess due to the dynamics of maturation and trafficking between the endosomal and lysosomal compartments.

In this study, diaminobenzidine (DAB) photoconversion was applied to correlate fluorescence and transmission electron microscopy investigating the intracellular fate of chitosan NPs in a neuronal cell line. This in vitro model was chosen due to the special relevance of neurons as target for chitosan NPs since these proved to cross the blood brain barrier. ${ }^{20-25}$

\section{Materials and Methods}

\section{Preparation of chitosan nanoparticles}

Chitosan glutamate (Protasan G213, Mw $300,000 \mathrm{Da}$, degree of acetylation $15 \%$, glutamic acid content $30-50 \%$ ) was obtained from
Correspondence: Prof. Manuela Malatesta, Dipartimento di Scienze Neurologiche, Neuropsicologiche, Morfologiche e Motorie, Sezione di Anatomia e Istologia, Università di Verona, Strada Le Grazie 8, 37134 Verona, Italy. Tel. +39.045 .8027157 - Fax: +39.045 .8027163 .

E-mail: manuela.malatesta@univr.it

Key words: nanoparticles, diaminobenzidine photoconversion, transmission electron microscopy.

Acknowledgements: this work was supported by Fondazione Cariverona, project Verona Nanomedicine Initiative. MC's fellowship was partially supported by the Fondo Docenti Ateneo (University of Verona). MG and VG are PhD students in receipt of a fellowship from the Dottorato di Ricerca in Biologia cellulare and in Genetics, Molecular and Cellular Biology, respectively (University of Pavia).

Confocal fluorescence micrographs were taken at the Centro Grandi Strumenti of the University of Pavia (http://cgs.unipv.it).

Received for publication: 19 March 2012. Accepted for publication: 27 March 2012.

This work is licensed under a Creative Commons Attribution NonCommercial 3.0 License (CC BYNC 3.0).

(C) Copyright M. Malatesta et al., 2012

Licensee PAGEPress, Italy

European Journal of Histochemistry 2012; 56:e20 doi:10.4081/ejh.2012.e20

Pronova Biomedical (Oslo, Norway). Fluorescein 5(6)-isothiocyanate (FITC, Mw 398.38) and tripolyphosphate pentasodium salt (TPP, Mw $367.9 \mathrm{Da}$ ) were purchased from Sigma-Aldrich Chemical Co. (Gillingham, UK). FITC-labelled chitosan was synthetized by adding $2.5 \mathrm{~mL}$ of FITC in methanol $(2 \mathrm{mg} / \mathrm{mL})$ to $5 \mathrm{~mL}$ of chitosan $(1 \% \mathrm{w} / \mathrm{v}$ in $0.1 \mathrm{~N}$ $\mathrm{CH}_{3} \mathrm{COOH}$ :methanol 1:1 v/v). The reaction was run for $3 \mathrm{~h}$ in the dark at room temperature. Then the labelled polymer was precipitated in $0.5 \mathrm{M} \mathrm{NaOH}$ (till to $\mathrm{pH} 10$ ). The precipitate was recovered by centrifugation at $25,000 \mathrm{rcf}$ (10 min) and washed in methanol:water (70:30 $\mathrm{v} / \mathrm{v})$. The washing and the pelletization were repeated until no fluorescence was detected in the supernatant (Luminescence Spectrophotometer LS 55, Perkin Elmer, Waltham, MA, USA). The labelled chitosan was then dissolved in $0.1 \mathrm{~N} \mathrm{CH}_{3} \mathrm{COOH}$ and dialyzed in the dark against water for 3 days. Finally, the FITClabelled chitosan was freeze-dried. The effective grafting of the polymer with FITC was assessed by ${ }^{1} \mathrm{H}$ NMR analysis (Avance ${ }^{\mathrm{TM}}$ Ultra Shield 400 working in FT, Bruker, Karlsruhe, Germany) and the labelling efficiency (\% FITC/FITC-labelled chitosan, w/w) was determined by measuring the fluorescence intensity of the FITC-labelled chitosan solution 
against standard solution of FITC.

Fluorescent NPs were prepared with FITClabelled chitosan $\left(1 \mathrm{mg} / \mathrm{mL}\right.$ in $\left.0.1 \mathrm{~N} \mathrm{CH}_{3} \mathrm{COOH}\right)$ by a modified method combining ionotropic gelation and ultrasonication treatment. ${ }^{26,27}$ Briefly, $2 \mathrm{~mL}$ of TPP aqueous solution ( 0.3 $\mathrm{mg} / \mathrm{mL}$ ), at constant rate of $0.5 \mathrm{~mL} / \mathrm{min}$, was added to $5 \mathrm{~mL}$ of $1 \mathrm{mg} / \mathrm{mL}$ chitosan glutamate acetic solution under Ultra-turrax (T 10 Ultraturrax, Ika, Staufen, Germany) stirring at $17,500 \mathrm{rpm}$ while ultrasonicated in a ultrasonic bath operating at $50 / 60 \mathrm{~Hz}$. NPs were recovered by centrifugation at $4^{\circ} \mathrm{C}$ at $16,400 \mathrm{rpm}$ for $10 \mathrm{~min}$ (Centrifuge 5417R, Eppendorf, Germany) and resuspended in $500 \mu \mathrm{L}$ of double-distilled water.

Diameter, polydispersity and Z-potential of FITC-labelled chitosan NPs were determined by dynamic light scattering using a NICOMP 380 ZLS apparatus (Particle Sizing Systems, Goleta, CA, USA). Samples were diluted with $10 \mathrm{mM} \mathrm{KCl}$ aqueous solution before measuring the particle size; sample run time was approximately of $15 \mathrm{~min}$ (1 min for Z-potential determination). All measurements were made in triplicate and mean values \pm SD were recorded

\section{In vitro cell culture}

Rat neuronal B50 cells $\left(5 \times 10^{3}\right)$ were grown in DMEM (Dulbecco Modified Eagles Medium) supplemented with $10 \%(\mathrm{v} / \mathrm{v})$ fetal calf serum, $1 \%(w / v)$ glutamine, $100 \mathrm{U}$ of penicillin and 100 $\mu \mathrm{g} / \mathrm{mL}$ streptomycin (Celbio, Milano, Italy), at $37^{\circ} \mathrm{C}$ in a $5 \% \mathrm{CO}_{2}$ humidified atmosphere. Cells were trypsinized when subconfluent and seeded on glass coverslips in 12 multiwell dishes for fluorescence and transmission electron microscopy. Two days after seeding, the initial medium was replaced with $450 \mu \mathrm{L}$ of fresh medium plus $50 \mu \mathrm{L}$ of fluorescent chitosan NP suspension. The incubation time with NPs varied from $10 \mathrm{~min}$ to $24 \mathrm{~h}$ (Figure 1).

\section{Cell viability assay}

To estimate the effect of NPs on cell viability, B50 cultures at all the NP incubation times were detached by mild trypsinization $(0.25 \%$ trypsin in PBS containing 0.05\% EDTA) and stained in suspension for 2 min with $0.1 \%$ Trypan blue in the culture medium: cells that were permeable to Trypan blue were considered as non-viable and their percentage was estimated by microscope counting on a Burker hemocytometer; cell samples not exposed to NPs were considered as controls. Results were expressed as the mean \pm SD of three independent experiments.

\section{Analysis of chitosan nanoparticles intracellular distribution}

After incubation with FITC-labelled NPs,
B50 cells were fixed for fluorescence microscopy with $4 \%(\mathrm{w} / \mathrm{v})$ paraformaldehyde in PBS, pH 7.4 (15 min at room temperature-RT). Some samples were stained for DNA with Hoechst $33258(1 \mu \mathrm{g} / \mathrm{mL}$ in PBS for $5 \mathrm{~min}$; Sigma-Aldrich, Buchs, Switzerland), rinsed in PBS, and mounted in a 3:1 mixture of glycerol:PBS (Calbiochem, Inalco, Milano, Italy): this allowed to visualize the intracellular presence of fluorescent NPs and verify their possible intranuclear location, at any incubation times. In order to investigate NP cellular uptake, some cells were pre-incubated with PKH26 Red Fluorescent Cell Linker (SigmaAldrich) to stain the plasma membrane, then incubated with NPs and finally fixed and processed for fluorescence microscopy as described above. An Olympus BX51 microscope equipped with a $100 \mathrm{~W}$ mercury lamp (Olympus Italia Srl, Milano, Italy) was used under the following conditions: $450-480 \mathrm{~nm}$ excitation filter (excf), $500 \mathrm{~nm}$ dichroic mirror (dm), and 515 $\mathrm{nm}$ barrier filter (bf) for FITC; $540 \mathrm{~nm}$ excf, $580 \mathrm{~nm} \mathrm{dm}$, and $620 \mathrm{~nm}$ bf for PKH26 red; 330 $385 \mathrm{~nm}$ excf, $400-\mathrm{nm} \mathrm{dm}$, and $420 \mathrm{~nm}$ bf, for Hoechst 33258. Images were recorded with an Olympus Magnifire digital camera system (Olympus Italia Srl), and stored on a PC by the Olympus software, for processing and printing.

For confocal laser scanning microscopy, a Leica TCS-SP system mounted on a Leica DMIRBE inverted microscope (Leica Microsystems, Milano, Italy) was used; for fluorescence excitation, an Ar/UV laser at $364 \mathrm{~nm}$ was used for Hoechst 33258, an Ar/Vis laser at 488 $\mathrm{nm}$ for FITC and an He/Ne laser at $543 \mathrm{~nm}$ for PKH26 red. Spaced $(0.5 \mu \mathrm{m})$ optical sections were recorded using a $63 \mathrm{x}$ oil immersion objective. Images were collected in the $1024 \times 1024$ pixel format, stored on a magnetic mass memory and processed by the Leica confocal software.Quantitative evaluation of NPs uptake was carried out by using an Olympus BX51 microscope: for each incubation time, at least 500 cells per sample were counted using a 40x objective lens and the percentage of cells containing at least one NP was calculated; moreover, the mean number of internalised NPs per cell was also calculated.

For transmission electron microscopy, B50 cells were processed as follows. Some B50 cells were fixed with $2.5 \%(\mathrm{v} / \mathrm{v})$ glutaraldehyde and $2 \%(\mathrm{v} / \mathrm{v})$ paraformaldehyde in $0.1 \mathrm{M}$ phosphate buffer, $\mathrm{pH} 7.4$, at $4^{\circ} \mathrm{C}$ for $1 \mathrm{~h}$, washed and incubated with 3,3' diaminobenzidine (DAB) (20 $\mathrm{mg} / 10 \mathrm{~mL}$ in Tris $\mathrm{HCl} 0.05 \mathrm{M}$, pH 7.6) under simultaneous irradiation with two 8W 0sram Blacklite 350 lamps for $2 \mathrm{~h}$ at room temperature (these lamps emits with high intensity in the spectral range between 430 and $470 \mathrm{~nm}$, thus being suitable for FITC excitation); the cells were then post-fixed with $1 \% \mathrm{OsO}_{4}$ and $1.5 \%$ potassium ferrocyanide at room tempera- ture for $1 \mathrm{~h}$, dehydrated with acetone and embedded in Epon. As controls, some samples were processed as described above but omitting both DAB incubation with and exposure to the excitation light. Some other cell samples, after aldehyde fixation, were incubated with DAB under light irradiation, dehydrated with ethanol and embedded in LRWhite resin.

Ultrathin sections were weakly stained with uranyl acetate and observed in a Philips Morgagni transmission electron microscope (FEI Company Italia Srl, Milano, Italy) operating at $80 \mathrm{kV}$ and equipped with a Megaview II camera for digital image acquisition.

\section{Results \\ Characterization of chitosan nanoparticles}

The successful FITC-labelling of chitosan glutamate was shown by ${ }^{1} \mathrm{H}$ NMR spectra with an evident peak of the fluorescein aromatic groups at about $7.00 \mathrm{ppm}$ (data not shown). The weight fraction of FITC per weight unit of chitosan was $2.7 \%(\mathrm{w} / \mathrm{w})$. The FITC-chitosan conjugate was successfully transformed by ionotropic gelation with TPP into NPs with a spherical shape (mean diameter $124.7 \pm 107.2$ $\mathrm{nm}$; Z-potential $10.51 \pm 1.2 \mathrm{mV}$ ).
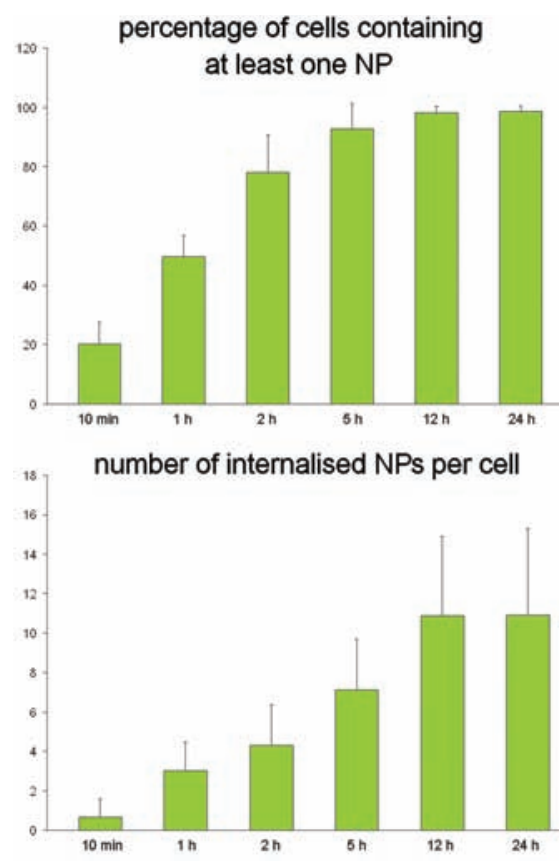

Figure 1. Mean $\pm S D$ values of the percentage of cells containing at least one NP and the number of internalised NPs per cell at the different incubation times. 


\section{Cell viability}

The incubation of cells with NPs for $10 \mathrm{~min}$ up to $24 \mathrm{~h}$ did not increase cell mortality: the Trypan blue exclusion test showed that dead cells were always less than $1 \%$ of the total cell population at no variance with control samples not exposed to NPs.

\section{Intracellular distribution of chitosan nanoparticles}

Fluorescence microscopy revealed that after 10 min incubation chitosan NPs already entered the neuronal cells; NP number per cell progressively increased with the incubation time (Figure 1); at $24 \mathrm{~h}$ (i.e., the longest incubation time considered in the present study) NPs were still present inside neuronal cells. NPs were found throughout cytoplasm, being mostly found in perinuclear position at incubation time $12 \mathrm{~h}$ and $24 \mathrm{~h}$. NPs were never observed inside the cell nucleus (Figure 2).

When cell cultures were pre-incubated with PHK26 to stain the plasma membrane before being incubated with FITC-labelled NPs, many internalised green-fluorescing NPs were found to co-locate with red-fluorescing intracellular membranes (Figure 3) thus suggesting that NPs were internalized via endocytosis.

At transmission electron microscopy chitosan NPs appeared as roundish moderately electron-dense structures, hardly distinguishable in the cytosol or inside the lysosomal compartments (not shown). However, after DAB photoconversion NPs were labelled with homogeneously distributed, dark, finely granular reaction product which made them unequivocally recognizable (Figure 4). Interestingly, NPs showed an evident electrondense granular precipitate in samples embedded both in epoxy resin after osmium post-fixation (Figure 4a-d) or in acrylic resin without osmium post-fixation (Figure 4e-f).

In all samples NPs were mostly found within electron-lucent vacuoles (one NP per vacuole); they were ubiquitously distributed in the cytoplasm, from the cell periphery (sometimes just beneath the plasma membrane) to the perinuclear region (often very close to the nuclear envelope) (Figure 4a-b). They were never observed inside the nucleus. Some NPs were also found to be free in the cytosol (Figure 4c). After 12 and $24 \mathrm{~h}$ incubation most of the NPs were found in perinuclear position, but never inside the cell nucleus. Moreover, after 12 and $24 \mathrm{~h}$ incubation, NPs were observed inside multivesicular or residual bodies (Figure 4d): their morphology was often severely altered in either organelles, so they were only recognizable from the dark reaction product.

\section{Discussion}

Since 1982, when the use of the fluorophore lucifer yellow for DAB photoconversion was first described, ${ }^{28}$ this technique has been applied in a variety of studies with different fluorophores to correlate light and electron microscopy. ${ }^{29,30}$ In fact, when a fluorophore is exposed to the light of an appropriate wavelength, the orbital electron relaxation, follow- ing the excitation from the ground state to a higher energy level, can generate highly reactive singlet oxygen, which in turn induces the oxidation of DAB into an electron-opaque osmiophilic precipitate. The DAB reaction product exhibits uniform, non-diffusible staining properties, thereby serving as a useful tool for subsequent investigation of cellular ultrastructure. At TEM, native chitosan NPs appeared homogeneous and moderately electron dense structures almost indistinguishable
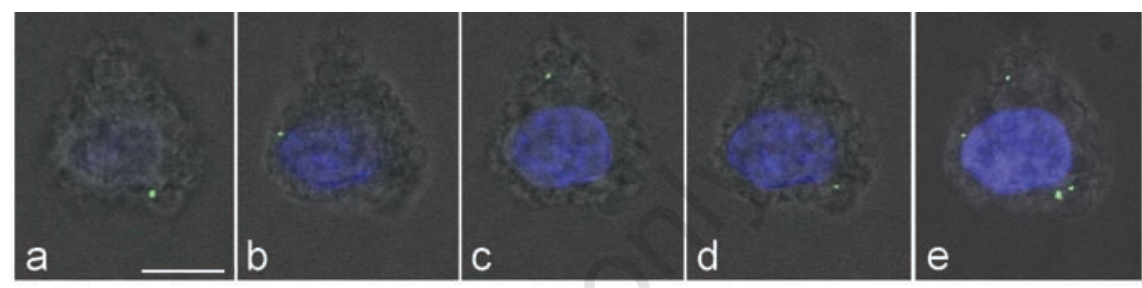

Figure 2. a-d) Confocal, $0.5 \mu \mathrm{m}$-spaced optical sections of a $\mathrm{B} 50$ cell after $2 \mathrm{~h}$ incubation with FITC-labelled NPs; e) merged image showing all the internalized NPs. Nuclear DNA was stained with Hoechst 33258. NPs are clearly located in the cytoplasm, but not in the nucleus. Scale bar: $10 \mu \mathrm{m}$.
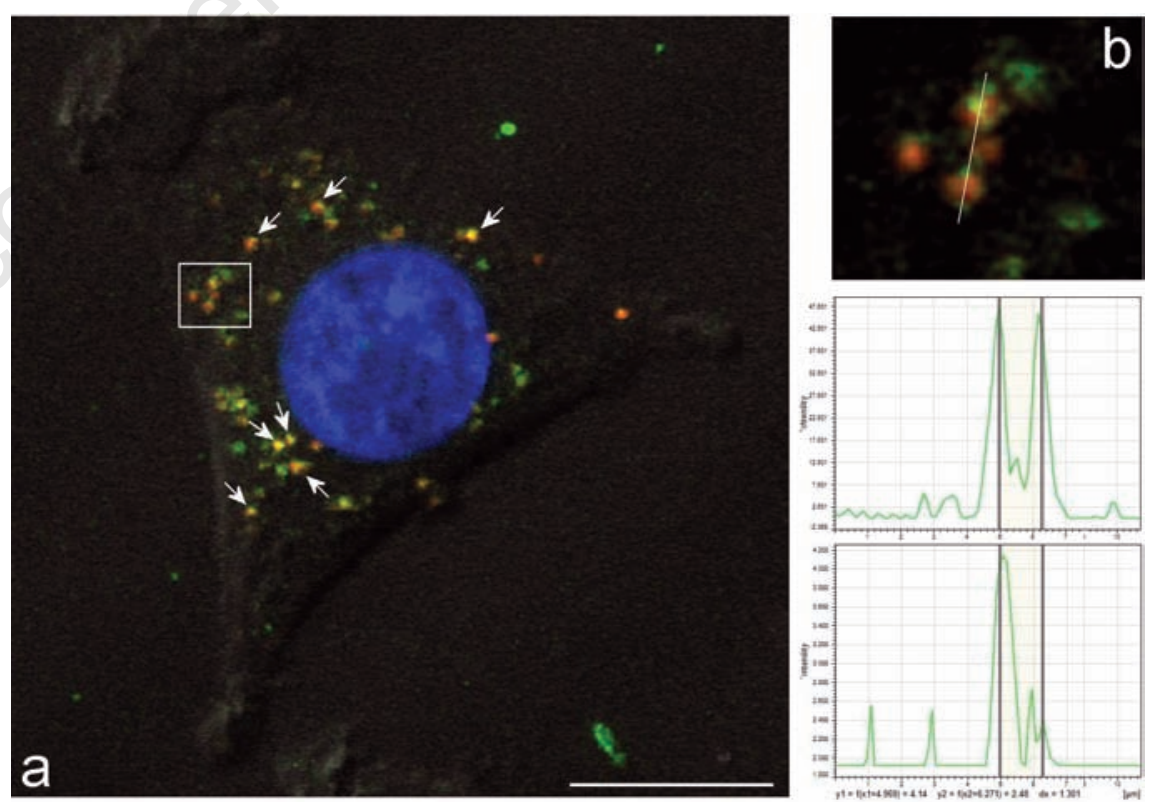

Figure 3. a) Confocal micrograph of a $B 50$ cell after 5 h incubation with FITC-labelled NPs; the cells were previously incubated with the red-fluorescing dye, BKH26 to label the plasma membrane. For several NPs (arrows), green and red fluorescence co-locate, as the result of the endocytotic internalization of part of the plasma membrane; b) higher magnification of the square box in a) showing two double-labelled NPs (upper panel): co-location of the fluorescence signals in a single optical section is confirmed by the histograms representing the region (line in the upper panel) where green and red fluorescence were measured (middle and lower panel, respectively). Scale bar: $10 \mu \mathrm{m}$. 
from the cytosolic milieu; in the present study, we demonstrated that $\mathrm{DAB}$ photoconversion is an especially suitable histochemical technique to unambiguously visualize fluorescently labelled chitosan NPs as well as to follow their intracellular fate. Interestingly, the DAB precipitate is easily detectable in both aldehydeosmium fixed, Epon-embedded samples (to be
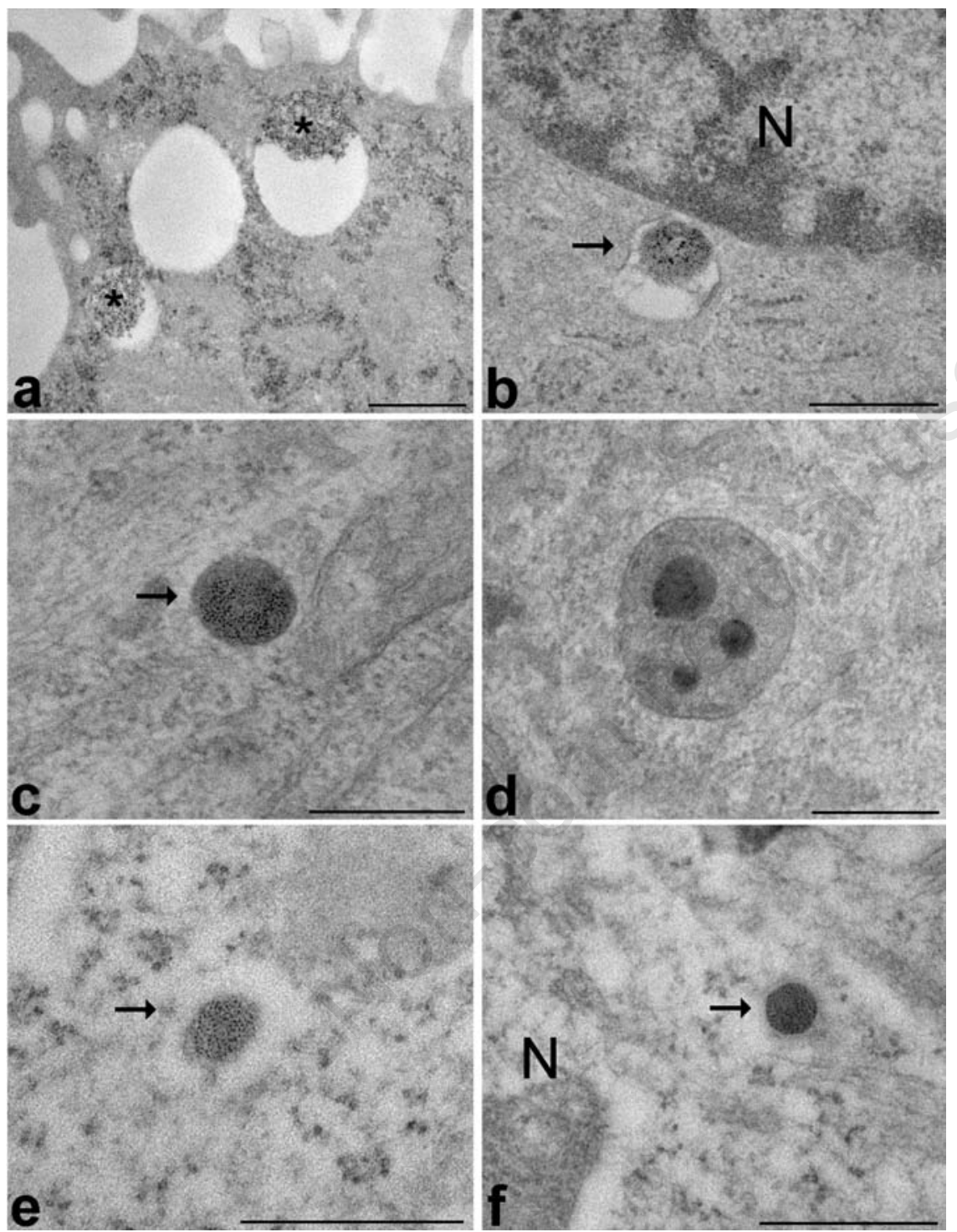

Figure 4. a-d) Transmission electron micrographs of B50 cells, aldehyde and osmium fixation, Epon embedding. a) Two NPs (asterisks) enclosed in endosomes at the cell periphery; both NPs show the fine granular, dark reaction product of DAB photoconversion; $b$ ) a NP enclosed in an endosome (arrow) is located very close to the nuclear envelope. N, nucleus; c) a NP (arrow) occurs free in the cytoplasm; d) a residual body contains three NPs still showing the photoconversion product; e,f) B50 cells, aldehyde fixation, LRWhite embedding; e) a NP is enclosed in an endosome (arrow); the lack of osmium fixation makes cell membranes hardly recognizable but the dark reaction product of DAB photoconversion is quite evident. $\mathrm{f}$ ) a NP (arrow) occurs free in the cytoplasm and close to the nucleus $(\mathrm{N})$. Scale bars: $500 \mathrm{~nm}$. tribution in vivo and ex vivo where very small chitosan NPs should preferably be used to cross biological barriers (especially the blood brain barrier). Combined fluorescence- and transmission electron microscopy demonstrated that chitosan NPs enter neuronal cells in culture by endocytosis and move through the cytoplasm to accumulate in the perinuclear region, frequently escaping the degrading action of lysosomal enzymes.

Our data are consistent with several reports on the internalization of chitosanbased NPs in different cell lines. . $^{13,16-19,31-34}$ Endocytosis is a conserved process in eukaryotes where extracellular substances are taken up by the cells usually through invagination of the plasma membrane to form vesicles. Cellular uptake of chitosan NPs seems to occur predominantly by adsorptive endocytosis initiated by nonspecific interactions between NPs and the plasma membrane. ${ }^{13,19}$ Co-localizing of NPs and the cell membrane marker PHK26 at fluorescence microscopy as well as finding of several NPs enclosed in vacuoles at TEM confirm this uptake modality also for B50 cells.

Several NPs were found to occur free in the cytoplasm i.e., devoid of a surrounding membrane. This is of special relevance to their pharmacological activity because it is known that chitosan-based NPs can protect incorporated drugs from enzymatic degradation, ${ }^{8}$ probably due to their capability of escaping from endosomes ${ }^{35-37}$ and entering the cytosol. ${ }^{18,38}$ This makes chitosan-based NPs particularly suitable to release drugs directly in the cytoplasm and for prolonged periods. Similarly to previous observation, ${ }^{16}$ some NPs were still recognizable inside multivesicular and residual bodies, suggesting that lysosomal degradation of NPs may take place through a clathrin-dependent pathway. ${ }^{13-19}$

Similarly to other cell lines, ${ }^{34}$ in B50 cells too internalized chitosan NPs migrate from the cell periphery to the perinuclear region: though still unexplained, NP accumulation close to the nuclear envelope represents a further positive property for drug delivery since it ensures higher drug concentration around the nucleus (which is often the main target for various, especially anticancer, drugs). In B50 cells, as already observed in other cell types, chitosan NPs were never found inside the nucleus. Since nuclear localization of different NPs has been reported in other cell models in vitro,,$^{12,39-41}$ we can hypothesize that cell line characteristics, the chemical-physical features of NPs, or both may account for this finding. It seems therefore important to test the nuclear accessibility for each cell line as well as for NP characteristics.

In conclusion, the DAB photoconversion 
technique allowed to demonstrate that chitosan NPs easily enter neuronal cells, where they localize both inside vesicles and free in the cytosol and accumulate around the cell nucleus: taking into account the well known ability of chitosan NPs to cross the blood brain barrier, this opens interesting and promising perspectives for their exploitation as intracellular drug carriers in vivo. ${ }^{20-25}$

\section{References}

1. Kumar MNVR. A review of chitin and chitosan applications. React Funct Polym 2000;46:1-27.

2. Freier T, Koh HS, Kazazian K, Shoichet MS. Controlling cell adhesion and degradation of chitosan films by $\mathrm{N}$-acetylation. Biomaterials 2005;26:5872-8.

3. Nordtveit RJ, Varum KM, Smidsrød 0. Degradation of fully water-soluble, partially N-acetylated chitosans with lysozyme. Carbohydr Polymers 1994;23:253-60.

4. Nordtveit RJ, Varum KM, Smidsrød 0. Degradation of partially $\mathrm{N}$-acetylated chitosans with hen egg white and human lysozyme. Carbohydr Polymers 1996;29: 163-7.

5. Rinaudo M. Chitin and chitosan: Properties and applications. Prog Polym Sci 2006; 31:603-32.

6. Janes KA, Fresneau MP, Marazuela A, Fabra A, Alonso MJ. Chitosan nanoparticles as delivery systems for doxorubicin. $\mathbf{J}$ Control Release 2001;73:255-67.

7. Wang JJ, Zeng ZW, Xiao RZ, Xie T, Zhou GL, Zhan XR, et al. Recent advances of chitosan nanoparticles as drug carriers. Int J Nanomedicine 2011;6:765-74.

8. Mao HQ, Roy K, Troung-Le VL, Janes KA, Lin KY, Wang Y, et al. Chitosan-DNA nanoparticles as gene carriers: synthesis, characterization and transfection efficiency. J Control Release 2001;70:399-421.

9. Janes KA, Calvo P, Alonso MJ. Polysaccharide colloidal particles as delivery systems for macromolecules. Adv Drug Deliv Rev 2001;47:83-97.

10. Illum L, Jabbal-Gill I, Hinchcliffe M, Fisher AN, Davis SS. Chitosan as a novel nasal delivery system for vaccines. Adv Drug Deliv Rev 2001;51:81-96.

11. Mansouri S, Lavigne P, Corsi K, Benderdour M, Beaumont E, Fernandes JC. Chitosan-DNA nanoparticles as nonviral vectors in gene therapy: strategies to improve transfection efficacy. Eur J Pharm Biopharm 2004;57:1-8.

12. Colonna C, Dorati R, Conti B, Modena T, Biggiogera M, Spedito A, et al. Induction of an in vitro reversible hypometabolism through chitosan-based nanoparticles. J Microencapsul 2011;28:229-39.

13. Huang M, Ma Z, Khor E, Lim L-Y. Uptake of FITC-chitosan nanoparticles by A549 cells. Pharm Res 2002;19:1488-94.

14. Ma Z, Lim L-Y. Uptake of chitosan and associated insulin in Caco-2 cell monolayers: a comparison between chitosan molecules and chitosan nanoparticles. Pharm Res 2003;20:1812-9.

15. Harush-Frenkel 0, Debotton N, Benita S, Altschuler Y. Targeting of nanoparticles to the clathrin-mediated endocytic pathway. Biochem Biophys Res Commun 2007;353: 26-32.

16. Nam HY, Kwon SM, Chung H, Lee SY, Kwon SH, Jeon H, et al. Cellular uptake mechanism and intracellular fate of hydrophobically modified glycol chitosan nanoparticles. J Control Release 2009;135: 259-67.

17. Park S, Lee SJ, Chung H, Her S, Choi Y, Kim K, et al. Cellular uptake pathway and drug release characteristics of drugencapsulated glycol chitosan nanoparticles in live cells. Microsc Res Tech 2010;73:85765.

18. Zaki NM, Nasti A, Tirelli N. Nanocarriers for cytoplasmic delivery: cellular uptake and intracellular fate of chitosan and hyaluronic acid-coated chitosan nanoparticles in a phagocytic cell model. Macromol Biosci 2011;11:1747-60.

19. Zhang H, Zhu D, Song L, Liu L, Dong X, Liu $\mathrm{Z}$, et al. Arginine conjugation affects the endocytic pathways of chitosan/DNA nanoparticles. J Biomed Mater Res A 2011;98:296-302.

20. Agyare EK, Curran GL, Ramakrishnan M, Yu CC, Poduslo JF, Kandimalla KK. Development of a smart nano-vehicle to target cerebrovascular amyloid deposits and brain parenchymal plaques observed in Azheimer's disease and cerebral amyloid angiopathy. Pharm Res 2008;25:267484.

21. Karatas H, Aktas Y, Gursoy-Ozdemir Y, Bodur E, Yemisci M, Caban S, et al. A nanomedicine transports a peptide caspase-3 inhibitor across the blood-brain barrier and provides neuroprotection. $\mathrm{J}$ Neurosci 2009;29:13761-9.

22. Songjiang Z, Lixiang W. Amyloid-Beta associated with chitosan nano-carrier has favorable immunogenicity and permeates the BBB. AAPS PharmSciTech 2009;10: 900-5.

23. Wang ZH, Wang ZY, Sun CS, Wang CY, Jiang TY, Wang SL. Trimethylated chitosan-conjugated PLGA nanoparticles for the delivery of drugs to the brain. Biomaterials 2010;31:908-15.

24. Tahara K, Miyazaki Y, Kawashima Y,
Kreuter J, Yamamoto H. Brain targeting with surface-modified poly(D,L-lactic-coglycolic acid) nanoparticles delivered via carotid artery administration. Eur J Pharm Biopharm 2011;77:84-8.

25. Jaruszewski KM, Ramakrishnan S, Poduslo JF, Kandimalla KK. Chitosan enhances the stability and targeting of immuno-nanovehicles to cerebro-vascular deposits of Alzheimer's disease amyloid protein. Nanomedicine 2012;8:250-60.

26. Tang ES, Huang M, Lim LY. Ultrasonication of chitosan and chitosan nanoparticles. Int J Pharm 2003;265:103-14.

27. Colonna C, Conti B, Perugini P, Pavanetto F, Modena T, Dorati R, et al. Chitosan glutamate nanoparticles for protein delivery: development and effect on prolidase stability. J Microencapsul 2007;24:553-64.

28. Maranto AR. Neuronal mapping: a photooxidation reaction makes Lucifer yellow useful for electron microscopy. Science 1982;217:953-5.

29. Sandell JH, Masland RH. Photoconversion of some fluorescent markers to a diaminobenzidine product. J Histochem Cytochem 1988;36:555-9.

30. Lübke J. Photoconversion of diaminobenzidine with different fluorescent neuronal markers into a light and electron microscopic dense reaction product. Microsc Res Tech 1993;24:2-14.

31. Jensen KD, Nori A, Tijerina M, Kopeckova P, Kopecek J. Cytoplasmic delivery and nuclear targeting of synthetic macromolecules, J Control. Release 2003;87:89-105.

32. Panyam J, Labhasetwar V. Dynamics of endocytosis and exocytosis of poly(D, Llactide- co-glycolide) nanoparticles in vascular smooth muscle cells. Pharm Res 2003;20:212-20.

33. Chiu YL, Ho YC, Chen YM, Peng SF, Ke CJ, Chen KJ, et al. The characteristics, cellular uptake and intracellular trafficking of nanoparticles made of hydrophobicallymodified chitosan. J Control Release 2010;146:152-9.

34. Yue ZG, Wei W, Lv PP, Yue H, Wang LY, Su ZG, et al. Surface charge affects cellular uptake and intracellular trafficking of chitosan-based nanoparticles. Biomacromolecules 2011;12:2440-6.

35. Sato T, Ishii T, Okahata Y. In vitro gene delivery mediated by chitosan. effect of $\mathrm{pH}$, serum, and molecular mass of chitosan on the transfection efficiency. Biomaterials 2001;22:2075-80.

36. Koping-Hoggard M, Tubulekas I, Guan H, Edwards K, Nilsson M, Varum KM, et al. Chitosan as a nonviral gene delivery system. Structure-property relationships and characteristics compared with polyethylenimine in vitro and after lung 
administration in vivo. Gene Ther 2001;8: 1108-21.

37. Kamiya H, Tsuchiya H, Yamazaki J, Harashima H. Intracellular trafficking and transgene expression of viral and nonviral gene vectors. Adv Drug Delivery Rev 2001;52:153-64.

38. Serda RE, Mack A, van de Ven AL, Ferrati S, Dunner K Jr, Godin B, et al. Logic-embed- ded vectors for intracellular partitioning, endosomal escape, and exocytosis of nanoparticles. Small 2010;6:2691-700.

39. Ding Y, Bian X, Yao W, Li R, Ding D, Hu Y, et al. Surface-potential-regulated transmembrane and cytotoxicity of chitosan/ gold hybrid nanospheres. ACS Appl Mater Interfaces 2010;2:1456-65.

40. Gaumet M, Gurny R, Delie F. Interaction of biodegradable nanoparticles with intestinal cells: the effect of surface hydrophilicity. Int J Pharm 2010;390:45-52.

41. Wang W, Jiang X, Chen K. Lanthanidedoped chitosan nanospheres as cell nuclei illuminator and fluorescent nonviral vector for plasmid DNA delivery. Dalton Trans 2012;41:490-7. 